\title{
Ultrastructure of euspermatozoa and paraspermatozoa in the volutid snail Adelomelon ancilla (Mollusca: Caenogastropoda)
}

\author{
S. Zabala $\cdot$ G. N. Hermida $\cdot$ J. Giménez
}

Received: 15 July 2008 / Revised: 11 December 2008 / Accepted: 9 January 2009 / Published online: 12 February 2009

(C) Springer-Verlag and AWI 2009

\begin{abstract}
The ultrastructure of the euspermatozoa and the paraspermatozoa is investigated in Adelomelon ancilla, through histological section observed by transmission electron microscopy. Euspermatozoa of A. ancilla consists of: (1) a conical acrosomal vesicle (with a short basal invagination, constricted anteriorly) which is flattened at the apex and associated with an axial rod, a centrally perforated basal plate and a short accessory membrane, (2) a rodshaped, solid and highly electron-dense nucleus (with a short basal fossa containing a centriolar complex and a initial portion of a $9+2$ axoneme), (3) an elongate midpiece consisting of the axoneme sheathed by 5-6 helical mitochondrial elements each exhibiting a dense U-shaped outer layer, (4) an elongate glycogen piece (where the axoneme is sheathed by nine tracts of glycogen granules), (5) a dense annulus at the junction of the midpiece and glycogen piece, and (6) a short free tail region (where the axoneme is surrounded only by plasma membrane). We observed a parasperm in A. ancilla. This is vermiform in shape and is composed of multiple axonemes and extensive cytoplasm
\end{abstract}

Communicated by H.D. Franke.

S. Zabala · J. Giménez $(\bowtie)$

Laboratorio de Invertebrados, DBBE,

Facultad de Ciencias Exactas y Naturales,

Universidad de Buenos Aires, Buenos Aires, Argentina

e-mail: jgimenez@bg.fcen.uba.ar

G. N. Hermida

Laboratorio de Histología Animal, DBBE,

Facultad de Ciencias Exactas y Naturales,

Universidad de Buenos Aires, Buenos Aires, Argentina

J. Giménez

CONICET, Museo Argentino de Ciencias Naturales,

Av. Ángel Gallardo 470, C1405DJR, Buenos Aires, Argentina with numerous vesicles, and mitochondria are scattered inside the axonemes. Sperm of $A$. ancilla is characterized by the euspermatozoa type 2 and the paraspermatozoa morphology belongs to type 5 . The $U$ shaped electrodense mitochondrial element in the midpiece of the eusperm and the constriction in the acrosomal vesicle present in A. ancilla are exclusive. We suggest that these characteristics could have taxonomic importance, because these was observed in other volutids and have not been observed in the rest of caenogastropods studies. We consider that the morphology of paraspermatozoa in A. ancilla corresponds to the "lancet" type.

Keywords Euspermatozoa $\cdot$ Paraspermatozoa · Morphology $\cdot$ Gastropods $\cdot$ Volutidae

\section{Introduction}

The morphological diversity of spermatozoa and the process of spermatogenesis are one of the tools that have been utilized for systematic and phylogenetic studies of gastropods, especially at or above the family level (Nishiwaki 1964; Giusti 1971; Melone et al. 1980; Healy 1982, 1983a, b, 1988, 1996a, b; Koike 1985; Thompson 1973). The systematic positioning and the construction of phylogenies of some groups are based on the ultrastructure of their spermatozoa. Sperm diversity reflects the environment of fertilization, as well as the systematic position and the phylogenetic relationships of the taxa that are being considered (Healy 1996a).

The production of dimorphic sperm is widespread among prosobranch mollusks, especially in caenogastropods (Melone et al. 1980; Nishiwaki 1964). This occurs when an organism produces both fertile sperm, the euspermatozoa, 
and sterile sperm, the paraspermatozoa (Buckland-Nicks et al. 2000). These two sperm types coexist in the same species as well as within the same individual (Suwanjarat and Suwaluk 2003).

Although the ultrastructure of caenogastropod sperm of has been studied in many families (Buckland-Nicks and Chia 1976; Buckland-Nicks et al. 2000; Healy 1982, 1986; Healy and Jamieson 1981) it has not been closely examined in the Volutidae. Only two species from this family have been studied: Zidona dufresnei (Donovan 1823) and Provocator mirabilis (Finlay 1926) (Giménez et al. 2008).

The marine snail, Adelomelon ancilla (Lightfoot 1786), inhabits shallow waters (5-15 $\mathrm{m}$ in depth) in the Patagonian littoral. Some species of the family Volutidae, such as A. ancilla, possess a importance as fisheries resource.

In the present study, we describe the ultrastructure of eupermatozoa and paraspermatozoa of A. ancilla. We might expect $A$. ancilla to have sperm ultrastructural similarities with other member of the Volutidae, such as $Z$. dufresnei and P. mirabilis. The ultrastructural descriptions in A. ancilla could utilize as comparative tools for systematic and may contribute to the understanding of the relationships among volutids and caenogastropods.

\section{Materials and methods}

Reproductively mature males of A. ancilla were collected in Punta Este, Golfo Nuevo, Chubut's province, Argentina $\left(42^{\circ} 42^{\prime} 24.1^{\prime \prime} \mathrm{S}\right.$ and $\left.65^{\circ} 06^{\prime} 20.9^{\prime \prime} \mathrm{W}\right)$, at depths of $5-10 \mathrm{~m}$ by scuba diving. After removal of the shell pieces of the testis, $\left(9 \mathrm{~mm}^{3}\right)$ they were fixed in Bouin's aqueous solution, dehydrated in a graded ethanol series and embedded in methacrylate for light microscopy. Serial sections $(5 \mu \mathrm{m}$ thick) were stained with a modified Masson's trichrome, and the periodic acid Shiff reaction (PAS) was used for the demonstration of neutral glycoconjugates. For transmission electron microscopy (TEM), tissues were fixed in $3 \%$ glutaraldehyde in $0.1 \mathrm{M}$ phosphate buffer $(\mathrm{pH} 7.4)$ for $4 \mathrm{~h}$ at $4^{\circ} \mathrm{C}$, and postfixed in $1 \%$ osmium tetroxide for $2 \mathrm{~h}$. Semithin and ultrathin sections, cut using a Reichert ultramicrotome, were stained with uranyl acetate and lead citrate. The sections were examined and photographed using Philips EM 301 transmission electron microscopes operated at 75$80 \mathrm{kV}$. Total of 50 sperms lengths were determined in five males by viewing and photographing tissue squashes using a Zeiss Axiostar light microscope.

\section{Results}

In A. ancilla the euspermatozoa and paraspermatozoa coexist within the same spermatogenic tubules. Euspermatozoa are composed of an anterior acrosomal complex followed by a rod-shaped nucleus, an elongate midpiece, a glycogen piece and an end piece. Paraspermatozoa are vermiform and are composed of multiple incorporated axonemes peripherally; within the cell body, different types of vesicles and mitochondria are present.

\section{Euspermatozoa}

\section{Acrosomal complex}

The anterior acrosomal complex consists of a tall, conical, membrane-bound acrosomal vesicle, an axial rod and a basal plate (Fig. 1a). The length of acrosomal vesicle is approximately $1.49 \pm 0.04 \mu \mathrm{m}$, and is electron-dense. Apically, the plasma membrane of the acrosomal vesicle is separated from the vesicle contents, forming the apical bleb (Fig. 1b). The acrosomal vesicle has a posterior invagination about $0.44 \mu \mathrm{m}$ long and constricted anteriorly (Fig. 1c). An axial rod is situated inside the invagination.

A basal plate is located between the acrosomal complex and the nucleus. An accessory membrane $(0.135 \mu \mathrm{m}$ in length) is observed between the plasma membrane and the acrosomal vesicle, in the posterior region of the acrosomal complex (Fig. 1a). Transverse sections at different levels of the acrosomal complex show a gradual change in the shape: from oval at the base to more laterally compressed in the anterior region of the acrosomal complex (Fig. 1d-g).

\section{Nucleus}

The nucleus is filiform, composed of a dense and homogenous material, with a short posterior invagination $(0.43 \mu \mathrm{m}$ in depth). The centriolar derivative is located within the invagination and is continuous with the initial portion of a $9+2$ microtubular pattern axoneme (Fig. 1h, j, k) .

\section{Midpiece}

Continuous with and posterior to the nucleus, the axoneme (exhibiting the typical microtubular pattern $9+2$ ) is sheathed by five to six helically arranged, elongate mitochondria. In longitudinal sections each mitochondrial element exhibits a U-shaped, bilaminar, outer layer that is notably more electro-dense than the rest of the mitochondrial material. In oblique longitudinal sections the mitochondrial elements are distinguished as a continuous sheath (Fig. 1i, 1).

\section{Annular complex and glycogen piece}

Immediately following termination of the midpiece, the axoneme becomes enclosed by nine continuous tracts of 
Fig. 1 Euspermatozoa of Adelomelon ancilla.

a Longitudinal section (LS) through acrosomal complex and anterior portion of nucleus.

b LS of the acrosomal complex in the anterior region. Note the apical bleb. c LS of the acrosomal complex. Note the constriction of the posterior acrosomal invagination (starting point indicated by arrow). $\mathbf{d}-\mathbf{g}$ Series of transverse sections (TS) from apical bleb region (d) to basal region (g) of the acrosomal vesicle. Note lateral flattening of the acrosomal complex beginning in anterior portion of the invagination (d-f) and the presence of the accessory membrane (g). $\mathbf{h}$ LS junction of nucleus (showing invagination and centriole/axoneme insertion) and anterior portion of midpiece. i LS of midpiece. Note helical mitochondrial elements (defined by dense U-shaped profiles of periphery). $\mathbf{j}$ TS of the nucleus in the middle region. $\mathbf{k}$ TS of the nucleus in posterior region, note centriolar fossa with axoneme. I TS of midpiece region, note the microtubular pattern $(9+2)$. $A$ acrosomal complex, $a b$ apical bleb, ar axial rod material, $A v$ acrosomal vesicle, am accessory membrane, $a x$ axoneme, $b p$ basal plate, $m$ mitochondrion, $m p$ midpiece, $N$ nucleus, $s m$ subacrosomal material, $U \mathrm{U}$-shaped defining edge of mitochondrial element
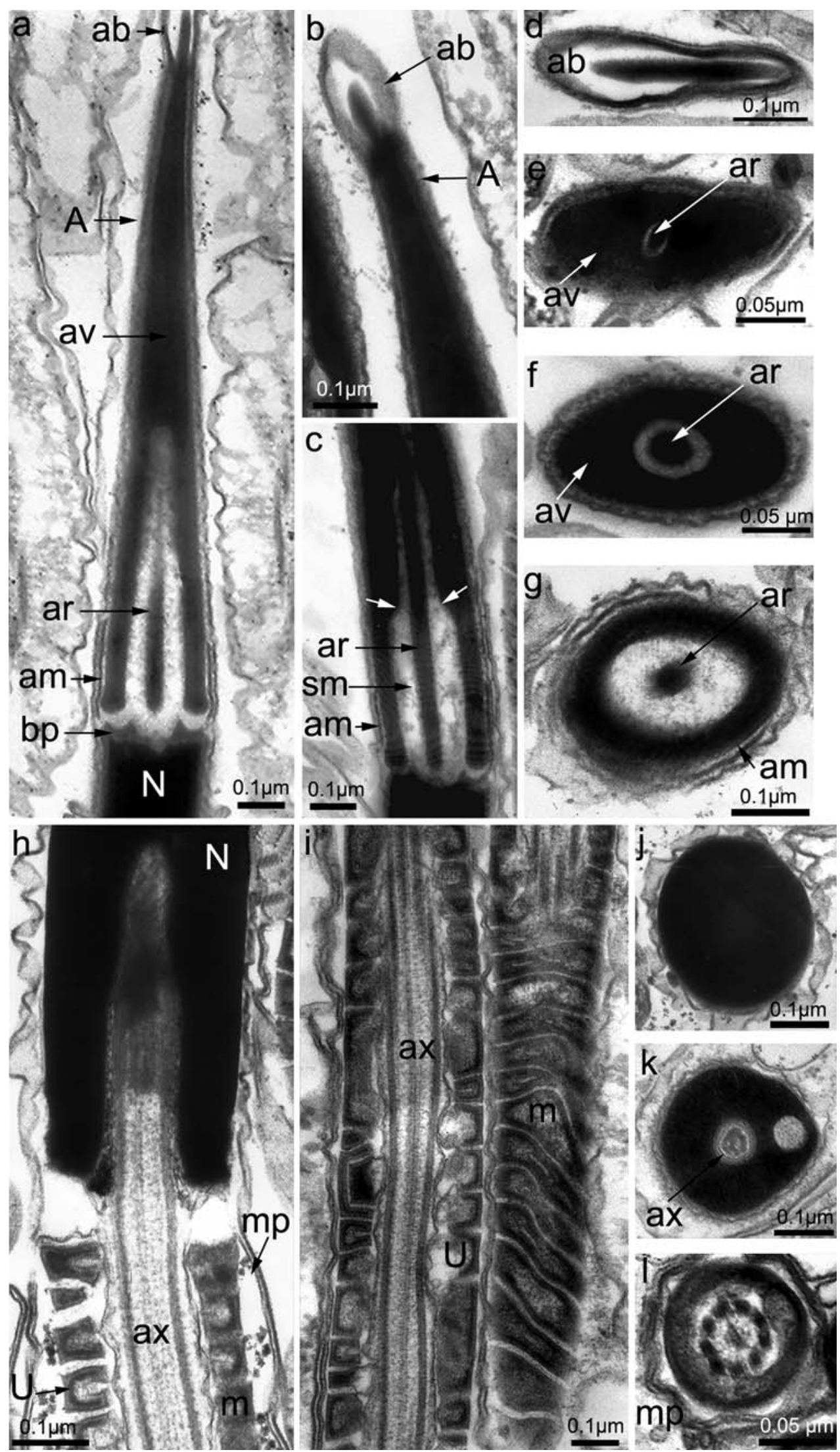
Fig. 2 Euspermatozoa of Adelomelon ancilla. a LS of the junction of midpiece and glycogen piece. Note annular complex. b LS of glycogen piece showing radiating, longitudinal rows of putative glycogen granules. c, d TS showing decrease in the diameter of glycogen piece towards posterior region of cell. e LS termination of glycogen piece and entire end piece region $\mathbf{f}$ TS of the end piece. an annulus complex, $a x$ axoneme, $e p$ end piece, $g$ putative glycogen granules, $g p$ glycogen piece, mp midpiece
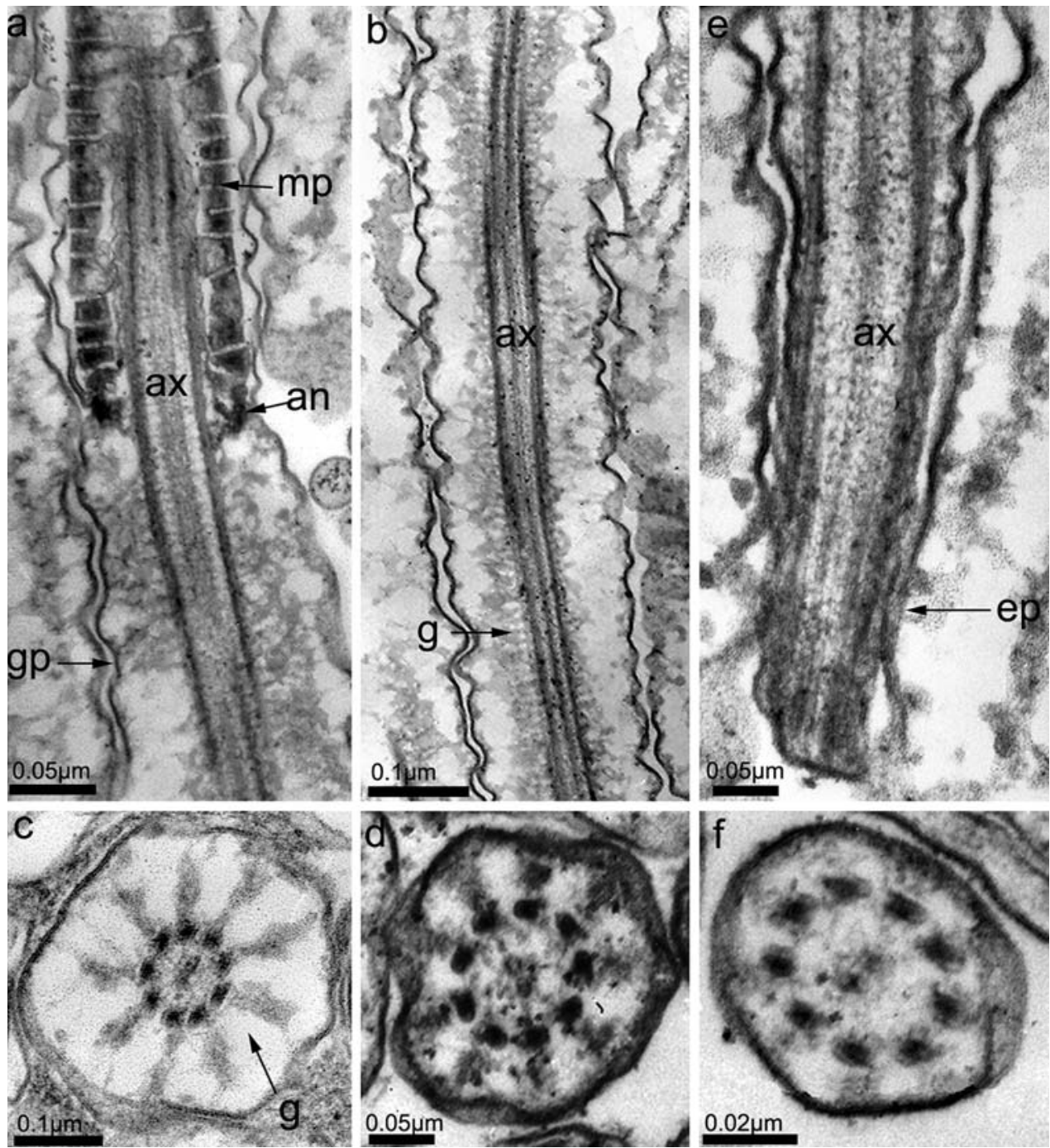

electron dense granules (Fig. 2c) and the plasma membrane to form the glycogen piece. In transverse sections each tract of granules is associated with one of the axonemal doublets, with the exception of the central pair (Fig. 2c, d). A dense double ring structure is present at the midpiece-glycogen piece junction (Fig. 2a, b). Transition to the end piece is gradual, with the diameter of granule sheath slowly diminishing until the axoneme is surrounded only by the plasma membrane (Fig. 2c-f). Using light microscopy we tested by cytochemical techniques that the glycogen piece is PAS positive.

\section{End piece}

The final piece is continuous with the glycogen piece and consists of the continuing $9+2$ microtubular pattern and is surrounded only by plasma membrane (Fig. 2e). The width measurement is approximately $0.08 \mu \mathrm{m}$ (Fig. 2f).

\section{Paraspermatozoa}

A. ancilla present a vermiform parasperm at least $120 \mu \mathrm{m}$ in length by light microscopy. The apex region is acidophilic and the paraspermatozoa cluster in cohorts close to, or in contact with, the tubular membrane (Fig. 3a). We tested by cytochemical techniques that the main body region of the paraspermatozoa is PAS positive. In transverse section the anterior region shows an electron-dense material around the axonemes peripherally, like a cap, a deposit of dense granular material is observed, and vesicles are not visible. Towards the apex of the paraspermatozoa the diameter decreases (Fig. 3b). On the other hand, the posterior region of parasperm, the axonemes, are situated peripherally (Fig. 3c).

One of the sections shows a main body region composed by: (1) peripherally distributed axonemes with the $(17 \pm 2$, $n=20)$ lying close to or in contact with the plasma mem- 
Fig. 3 Paraspermatozoa of Adelomelon ancilla. a Light microscope image. Modified Masson's trichrome. General view of the paraspermatozoa showing a vermiform aspect. Note the acidophilic area in the apex. b Transverse sections (TS) through apex showing electrondense material enclosing axonemes. $\mathrm{c}$ TS posterior section showing peripheral axonemes. d LS main body region of paraspermatozoa with dense vesicles present. e TS of paraspermatozoa showing 52 axonemes. Note the spiral disposition of the axonemes. f TS main body region contains dense vesicles and a large mitochondrion, showing 18 peripheral axonemes. $g$ TS main body region contains dense vesicles, mitochondrion, and axonemes in internally and peripherally. h Seminal vesicle, paraspermatozoa join to euspermatozoa $a x$ axoneme, $m$ mitochondrion, $p z$ paraspermatozoa, $d v$ dense vesicles

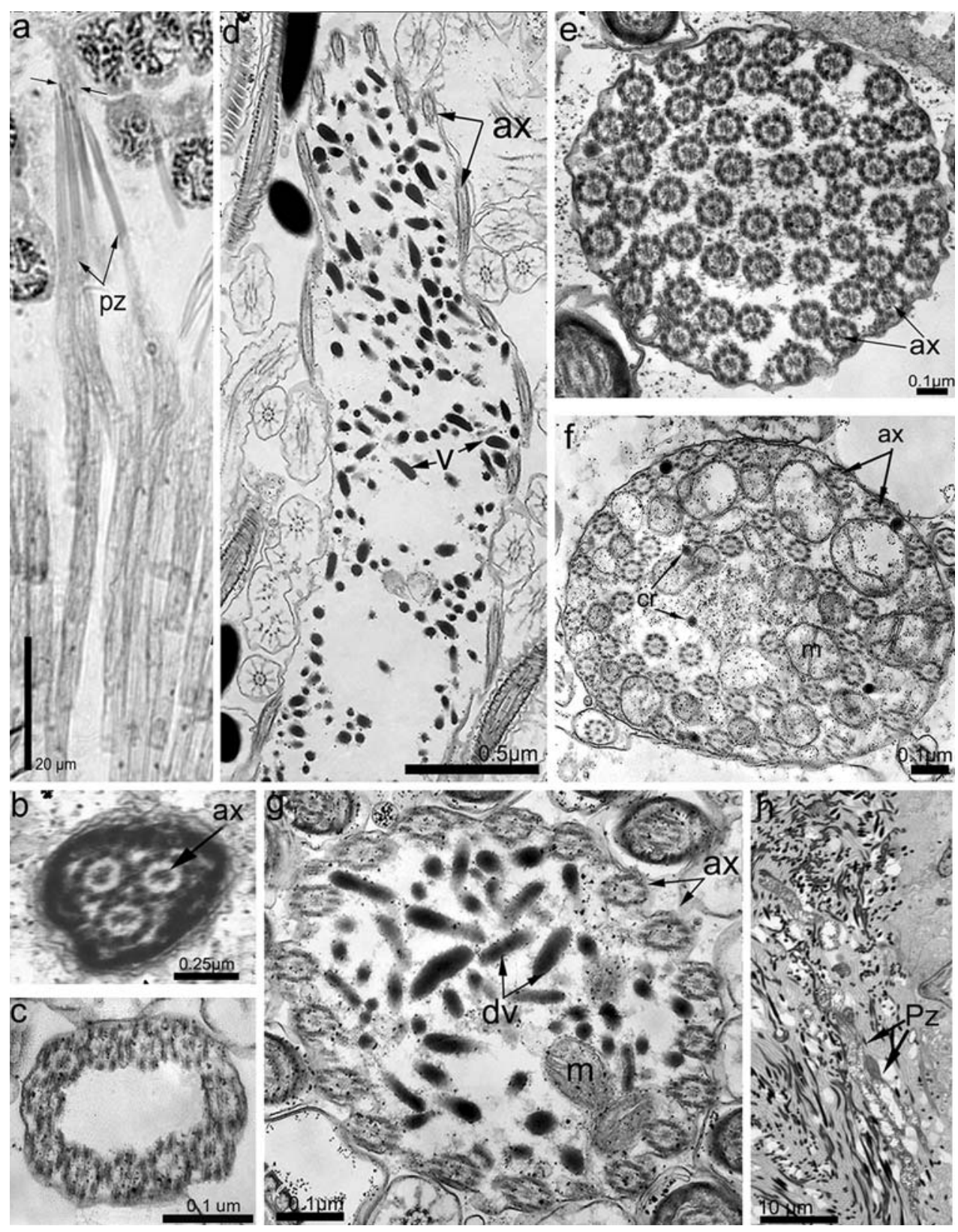

brane (axonemes approximately equidistant from each other), (2) numerous vesicles containing dense granular material but no obvious internal structure, (3) a few elongate mitochondria, and (4) a diffuse cytoplasmic matrix (Fig. 3d, g).

Two different transverse sections of parasperm are observed: one the disposition of axonemes distributed internally and peripherally ( $52 \pm 2, n=18)$ (Fig. 3e); the other one, the axonemes distributed peripherally $(18 \pm 2, n=18)$ and internally $(21 \pm 2, n=10)$. Vesicles and mitochondria are observed inside it (Fig. 3f).

Semithin sections by light microscope paraspermatozoa were found in the seminal vesicle, join to euspermatozoa (Fig. 3h).

\section{Discussion}

Structural comparison, euspermatozoa and paraspermatozoa

Most features of A. ancilla euspermatozoa can be observed in many other neogastropods and in the higher mesogastropods (Buckland-Nicks and Chia 1973; Healy 1982) characterized by the euspermatozoa type 2 described by Healy (1996b). These shared characters include: (1) morphology of the acrosomal complex (apical bleb, accessory membrane, shape of the acrosomal vesicle and the axial rod material), (2) a solid electron-dense nucleus, (3) midpiece composed of the axoneme surrounded by multiple (6-10) 
helically coiled mitochondria, (4) glycogen piece with nine tracts of granules associated with the axonemal doublets, and (5) presence of a dense ring structure at midpiece-glycogen piece junction.

The morphology of paraspermatozoa of A. ancilla belongs to type 5 paraspermatozoa of Nishiwaki (1964) (vermiform paraspermatozoa, exhibiting multiple peripheral axonemes, enclosed at maturity and bunched anteriorly; scattered mitochondria and small dense vesicles; and total absence of nuclear material).

\section{Euspermatozoa}

General features of the acrosomal complex in A. ancilla are shared with other caenogastropods (Healy 1983a, 1996b; Koike 1985), except for mitochondrial element and the constriction in the posterior acrosomal invagination (Fig. 4a), which only is shared with $Z$. dufresnei (Giménez et al. 2008).

Many neogastropods and some mesogastropods, like Potamididae, show the mitochondrial elements uniformly electron-dense (Kohnert and Storch 1984; Koike 1985) or present a non-helical arrangement of mitochondrial elements (Suwanjarat and Suwaluk 2003), respectively. In A. ancilla we found the outer layer of each mitochondrial element considerably more electron-dense than the remainder of the matrix component (which shows a U-shape in longitudinal section profile), the number of mitochondria was taken from previous stages of spermatogenesis (data unpublished) and there was a spiraling of the mitochondrial elements, as in Z. dufresnei and P. mirabilis (Giménez et al. 2008).

The glycogen piece of A. ancilla does not differ in any respect from the configuration shown to exist in many other caenogastropods (Healy 1983a; Kohnert and Storch 1984; Koike 1985), showing the typical microtubular pattern $(9+2)$ associated with glycogen granules for each pair. The junction between the midpiece and glycogen piece presents a complex of ring elements attached to the plasma membrane, as in many caenogastropods (Buckland-Nicks and Chia 1973; Buckland-Nicks et al. 1982a, b; Healy 1986, 1988; Healy and Jamieson 1993; Giménez et al. 2008). This complex structure of double ring differs from the annulus of other groups, which have a single ring, as Cerithioidea family (Caenogastropoda) (Healy 1982, 1983a).

\section{Paraspermatozoa}

Vermiform paraspermatozoa are present in most of Neotaenioglossa and Neogastropoda (see Nishiwaki 1964; Tochimoto 1967; Melone et al. 1980; Healy 1988; Hodgson 1997; Buckland-Nicks 1998). Buckland-Nicks et al. (1982a)
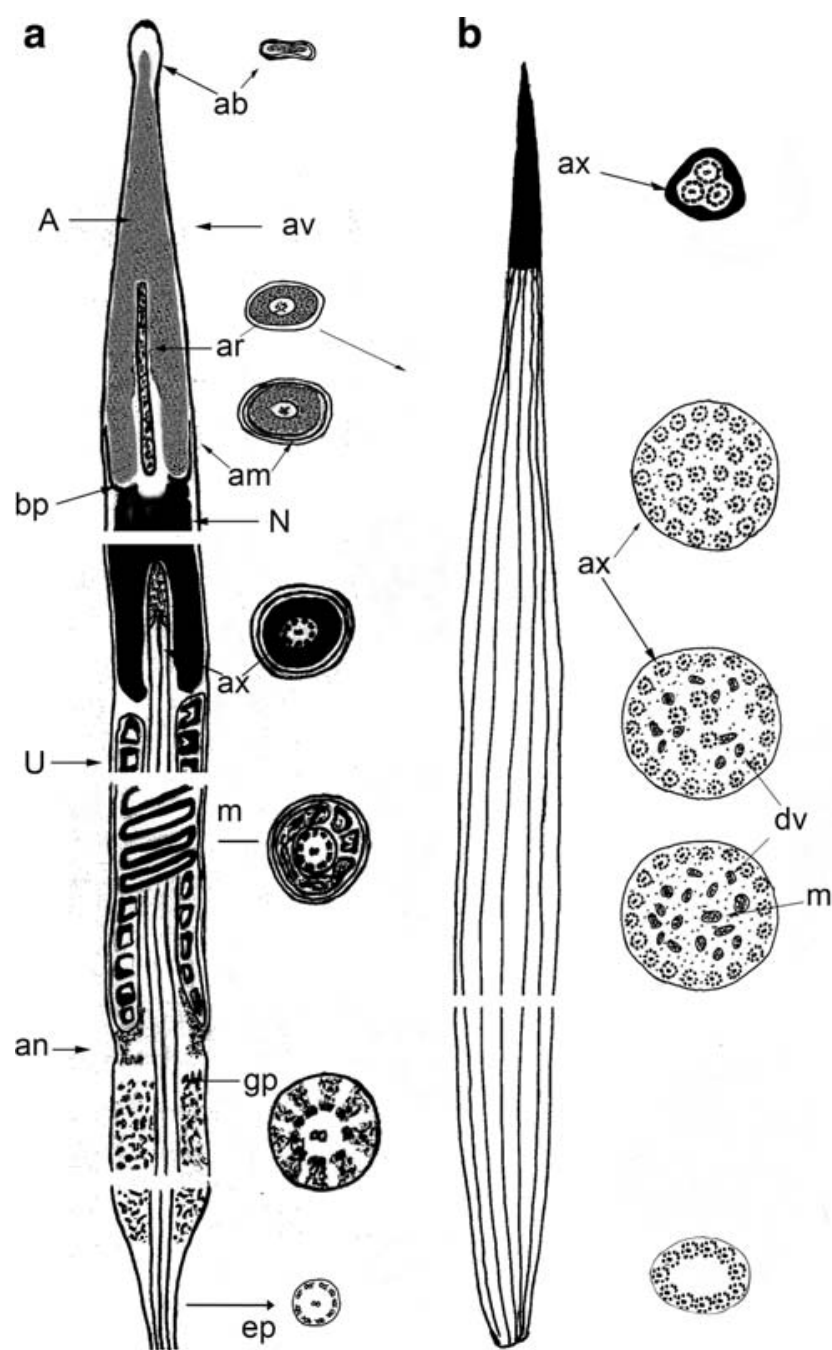

Fig. 4 Diagram of spermatozoa of Adelomelon ancilla. a Internal view of eusperm. TEM. Note the constriction of subacrosomal invagination and the U-shape of electron-dense mitochondrial elements in the midpiece. b External and general view of parasperm. Light microscopy. Trasversal sections observed by TEM. Note the TS of the apical, medial, and final region. $A$ acrosomal complex, $a b$ apical bleb, ar axial rod material, $a v$ acrosomal vesicle, am accessory membrane, an annulus, $a x$ axoneme, $b p$ basal plate, $c t$ acrosomal vesicle constriction, $d v$ dense vesicles, $e p$ endpiece, $g$ putative granules, $g p$ glycogen piece, $m$ mitochondria, $m p$ midpiece, $N$ nucleus, $U$ U-shaped defining edge of mitochondrial element. Not drawn exactly to scale

describe two types of vermiform paraspermatozoa: the bulkier "carrier" type which has many euspermatozoa attached and contains very large, dense vesicles and approximately 112 axonemes, and the smaller "lancet" type which never physically associates with euspermatozoa.

Adelomelon ancilla present the vermiform lancet type of parasperm (Fig. 4b). The parasperm consist of a conical anterior region, where the number of axonemes decrease and they are embedded in electron-dense material in the anterior region. This structure was observed in another 
caenogastropods as Fusitron and Ceratostoma (BucklandNicks 1998) and recently in the volutid Z. dufresnei (Giménez et al. 2008). Posteriorly, the numbers of axonemes increase and centriolar rootlets are present. Transversal section through the parasperm shows the increment of vesicles and decrease in the number of axonemes.

In other caenogastopods, paraspermatozoa are clustered in cohorts of either four or eight parasperm linked by cytoplasmic bridges (Buckland-Nicks 1998). In A. ancilla this disposition of parasperm was observed; however, the cytoplasmic bridges were not observed.

Functional considerations of paraspermatozoa

Alternative theories have been advanced in an attempt to answer the role of paraspermatozoa in the reproductive cycle. Many workers (Buckland-Nicks and Chia 1976) consider the function of nutrition and/or stimulation of euspermatozoa by the products of paraspermatozoan breakdown. Fretter and Graham (1962) suggest the 'transportation' of euspermatozoa during and after sperm transfers from male to female, via mobile associations of euspermatozoa. Buckland-Nicks (1998) suggest paraspermatozoa may be involved in creating a hostile pre-fertilization environment for rival sperm. In this context, lancet parasperm form a sperm plug in the bursa copulatrix that binds eusperm in the lumen.

These processes are poorly understood in snails but are central to our understanding of the role of parasperm in reproduction (Buckland-Nicks 1998).

The function of paraspermatozoa in A. ancilla may be involved in nutrition or stimulation of the eusperm; euspermatozoa and paraspermatozoa were found in the seminal vesicle together. Despite this more intensive studies are needed, as to determinate if the paraspermatozoa are present in the bursa copulatrix.

\section{Systematic considerations}

We consider that the U shaped electron-dense mitochondrial elements in the midpiece of the eusperm present in A. ancilla, Z. dufresnei and P. mirabilis and the constriction in the posterior acrosomal invagination in A. ancilla and $Z$. dufresnei are diagnostic at list to the family level. We suggest that these characteristics could have taxonomic importance, because these have not been observed in other caenogastropods. Furthermore, there are not enough investigations of sperm ultrastructure in Volutidae. Just knowing the ultrastructure of these species, we cannot assure that these characters are comparable for the Volutidae or Zidoninae. Further studies in sperm ultrastructure are needed in other volutids such as Odontocymbiolinae to confirm this hypothesis.
Acknowledgments Financial support for this project was provided Agencia de Promoción Científica PICT-14419. Jennifer Antonides for her help in English version and improvement of this manuscript.

\section{References}

Buckland-Nicks JA (1998) Prosobranch parasperm: sterile germ cells that promote paternity? Micron 29:267-280

Buckland-Nicks JA, Chia F (1973) The fine structure of the spermatozooan of Littorina (Gastropoda: Prosobranchia), with special reference to sperm motility. Zeitschrift für Zellforschung 144:111-129

Buckland-Nicks J, Chia F (1976) Spermatogenesis of a marine snail, Littorina sitkana. Cell Tissue Res 170:455-475

Buckland-Nicks JA, Williams D, Chia FS, Fontaine A (1982a) The fine structure of the polymorphic spermatozoa of Fusitriton oregonensis (Mollusca: Gastropoda), with notes on the cytochemistry of the internal secretions. Cell Tissue Res 227:235-255

Buckland-Nicks JA, Williams D, Chia FS, Fontaine A (1982b) Studies on the polymorphic spermatozoa of a marine snail. I-Genesis of the apyrene sperm. Biol Cell 44:305-314

Buckland-Nicks J, Healy J, Jamieson BG, Leary S (2000) Paraspermatogenesis in Littoraria (Palustorina) articulata, with reference to other Littorinidae (Littorinidea, Caenogastropoda). Inv Biol 119:254-264

Fretter V, Graham A (1962) British prosobranch molluscs: their functional anatomy and ecology. The Ray Society series, 144. Ray Society, London, p 755

Giménez J, Healy J, Hermida G, Lo Nostro F, Penchaszadeh P (2008) Ultrastructure and potential taxonomic importance of euspermatozoa and paraspermatozoa in the volutid gastropods Zidona $\mathrm{du}$ fresnei and Provocator mirabilis (Caenogastropoda, Mollusca). Zoomorphol 127:161-173

Giusti F (1971) L'ultrastruttura dello spermatozoo nella filogenesi e nella sistematica dei molluschi gasteropodi. Atti della Societa Italiana di Scienze Naturali e Museo Civico di Storia Naturale Milano 112:381-402 (in Italian)

Healy JM (1982) An ultrastructural examination of developing and mature euspermatozoa in Pyrazus ebeninus (Mollusca, Gastropoda, Potamididae). Zoomorphol 100:157-175

Healy JM (1983a) Ultrastructure of euspermatozoa of cerithiacean gastropods (Prosobranchia: Mesogastropoda). J Morphol 178:57-75

Healy JM (1983b) Ultrastructure of euspermiogenesis in the mesogastropod Stenothyra sp. (Prosobranchia, Rissoacea, Stenothyridae). Zool Scr 12:203-214

Healy JM (1986) An ultrastructural study of euspermatozoa, paraspermatozoa and nurse cells of the cowrie Cypraea errones (Gastropoda, Prosobranchia, Cypraeidae). J Molluscan Stud 52:125-137

Healy JM (1988) Sperm morphology and its systematic importance in the Gastropoda. In: Ponder WF (ed) Prosobranch phylogeny. Malacol Rev (Suppl) 4:251-266

Healy JM (1996a) An ultrastructural study of euspermatozoa in Bembicium auratum including a comparison with other Caenogastropoda, especially Littorinoidea. J Molluscan Stud 62:57-63

Healy JM (1996b) Molluscan sperm ultrastructure: correlation with taxonomic units within the Gastropoda, Cephalopoda and Bivalvia. In: Taylor J (ed) Origin and evolutionary radiation of the Mollusca. Oxford University Press, Oxford, pp 99-113

Healy JM, Jamieson BG (1981) An ultraestructural examination of developing and mature paraspermatozoa in Pyrazeus ebenius (Mollusca, Gastropoda, Potamididae). Zoomorphol 98:101-119

Healy JM, Jamieson BGM (1993) Euspermatozoa, paraspermatozoa and spermatozeugmata of Littorina (Palustorina) articulata (Prosobranchia: Caenogastropoda) with special reference to the pseudotrich. Acta Zool 74:321-330 
Hodgson AN (1997) Paraspermiogenesis in gastropod molluscs. Invertebr Reprod Dev 31:31-38

Kohnert R, Storch V (1984) Vergleichend-ultrastrukturelle Untersuchungen zur Morphologie eupyrener Spermien der Monotocardia (Prosobranchia). Zool Jahrb 111:51-93

Koike K (1985) Comparative ultrastructural studies on the spermatozoa of the Prosobranchia (Mollusca: Gastropoda). Sci Rep Fac Educ Gunma Univ 34:33-153

Melone G, Lora Lamia Donin D, Cotelli F (1980) The paraspermatic cell (atypical spermatozoon) of Prosobranchia: a comparative ultrastructural study. Acta Zool 61:191-201
Nishiwaki S (1964) Phylogenetical study on the type of the dimorphic spermatozoa. In: Prosobranchia. Sci Rep Tokyo Kyoiku Daigaku Sect B 11:237-275

Suwanjarat J, Suwaluk S (2003) Euespermatozoa structure and euespermiogenesis in Cerithidea cingulata (Gmelin, 1971) (Caenogastropoda: Potomididae). J Sci Technol 25:413-422

Thompson TE (1973) Euthyneuran and other molluscan spermatozoa. Malacologia 14:167-206

Tochimoto T (1967) Comparative histochemical study on the dimorphic spermatozoa of the Prosobranchia with special reference to polysaccharides. Sci Rep Tokyo Kyoiku Daigaku 13:75-109 